\title{
Interactive comment on "Hydrodynamic characterization of past flash-flood events and their associated hazards from dendrogeomorphological evidence in Caldera de Taburiente National Park (Canary Islands, Spain)" by Julio Garrote et al.
}

Anonymous Referee \#1

Received and published: 17 August 2016

The paper presents an interesting case study. In the process of reconstructing the characteristics of a flash flood event, rainfall information and proxi-information (dendrogeomorphological) provide highly inconsistent results. The flood peak discharge estimated by rainfall runoff modelling is more than one order of magnitude lower than the one obtained by fitting the water stages to the scars of trees with an hydraulic model. The paper rightly suggests that there is a benefit in performing analyses with different data since the contrasting results warn us on the fact that some more analysis

Printer-friendly version

Discussion paper 
is necessary to find out what really was the order of magnitude of the flood peak.

Despite the interesting case study, I do not like the paper and recommend rejection for the following reasons:

- I do not think that the statistical analysis of rainfall data is correct. I am surprised that the GEV and POT-GP method give such different results. In theory they should be analogous (being a Pareto distribution for peak-over-threshold mathematically correspondent to a GEV distribution for annual maxima). Is it because of the method used to estimate the parameters? I strongly recommend to add the plotting position representation of the data in figure 8 (which, by the way, should have rainfall and not flood peak in the $y$-axis). This would show where the estimation problem has gone wrong.

- I do not agree with the strategy of using over sofisticated methods when order of magnitudes are of interest. For instance, in section 3.2.2 the method for modelling the routing of the flood wave is presented, which require LIDAR data for the channel morphology. This is coupled with a very crude ranoff generation model (SCS-CN method + unit hydrograph with parameters estimated from empirical formulae) forced by highly uncertain rainfall inputs. What is the rationale for doing this? Much better would be to use simple models and account for the uncertainties involved. I strongly disagree with the "Future prospect" section of the paper, which suggests to use more complex models in the future. This will add other uncertainties and will not solve those discussed within this paper.

- The title and abstract state that a frequency analysis of (8?) past flash-flood events is performed. In reality only one event is analysed and the probability of exceeding such an event has not been estimated. The "Conclusion" section does not say what the paper contains.

- The methodologies used have not been presented clearly. For instance, what is the "SQRT-ETMAX method"? What is the "RMSE over disturbed tree sample"? What model has been used to generate synthetic hyetographs? How have the daily precipi-

Printer-friendly version

Discussion paper 
tation observations been used to constrain the generated hourly timeseries?

Interactive comment on Nat. Hazards Earth Syst. Sci. Discuss., doi:10.5194/nhess-2016-206, 2016.

Interactive

comment 